\title{
Acción del veneno de Bothrops diporus (yarará chica) del nordeste argentino sobre la hemostasia en diferentes mamíferos
}

\author{
Maruñak, S.'; Nuñez, S. ${ }^{2}$; Fernandez, C. ${ }^{1}$; Leiva, L. ${ }^{3}$; Acosta de Pérez, O. ${ }^{1}$ \\ ${ }^{1}$ Cátedra de Farmacología, ${ }^{2}$ Cátedra de Inmunología, Facultad de Ciencias Veterinarias, UNNE, Sargento \\ Cabral 2139, Corrientes (3400), Argentina. Tel. 03783-425753, E-mail: patmed@vet.unne.edu.ar. ${ }^{3}$ Laboratorio \\ de Química Biológica I, Facultad de Ciencias Exactas y Naturales y Agrimensura, Universidad Nacional del \\ Nordeste (UNNE).
}

\begin{abstract}
Resumen
Maruñak, S.; Nuñez, S.; Fernandez, C.; Leiva, L.; Acosta de Pérez, O.: Acción del veneno de Bothrops diporus (yarará chica) del nordeste argentino sobre la hemostasia en diferentes mamíferos. Rev. vet. 21: 1, 43-47, 2010. Los venenos de serpientes inducen gran variedad de efectos sobre la coagulación sanguínea debido a sus componentes coagulantes y anticoagulantes. En este trabajo se estudió el efecto del veneno de Bothrops diporus de Argentina sobre el sistema hemostático en diferentes especies de mamíferos, determinándose las actividades coagulante, fibrinolítica y letal. Se pudo comprobar que el veneno de esta serpiente genera desórdenes de la coagulación sanguínea atribuibles a enzimas de tipo trombinas que inducen la transformación del fibrinógeno a fibrina, registrándose mayor susceptibilidad en las especies ovina y humana. La dosis coagulante mínima se comparó con venenos de víboras centroamericanas, surgiendo que las serpientes de zonas más cálidas poseen menor actividad coagulante.
\end{abstract}

Palabras clave: Bothrops diporus, veneno, hemostasia, mamíferos.

\begin{abstract}
Maruñak, S.; Nuñez, S.; Fernandez, C.; Leiva, L.; Acosta de Pérez, O.: Effect of venom of Bothrops diporus from northeast Argentina on hemostatic system in different mammals. Rev. vet. 21: 1, 43-47, 2010. Snake venoms induce a wide variety of disorders, some of them on blood coagulation, since they contain both coagulant and anticoagulant components. In this assay we present the effects of venom of Bothrops diporus from Argentina on the hemostatic system of different mammal species, in order to estimate blood-clotting, fibrinolytic, and lethal activities. From our results, it can be stated that this venom has trombinlike enzymes that produced coagulation of plasma, being ovine and human the most sensitive species. Minimum coagulant dose for this venom was compared to those from Central America (Bothrops asper, Costa Rica), suggesting that venom of snakes from warmer areas have less coagulant activity.
\end{abstract}

Key words: Bothrops diporus, venom, hemostatic system, mammals.

\section{INTRODUCCIÓN}

El litoral argentino es habitado por varias especies de serpientes de la familia Viperidae, entre ellas Bothrops alternatus (yarará grande) y Bothrops diporus (yarará chica). Cuando se sienten agredidos, estos animales ponen en marcha un mecanismo de defensa que consiste en morder a la víctima, ocasionando una intoxicación de gravedad variable, debida a la difusión inmediata del veneno hacia los tejidos circundantes a la mordedura, simultánea a la absorción y distribución sistémica mediada por la circulación sanguínea y linfática. Los accidentes ofídicos producidos por las especies del género Bothrops se caracterizan por alteraciones loca-

Recibido: 31 mayo 2010 / Aceptado: 29 junio 2010 les como edema, hemorragia, necrosis muscular ${ }^{1,7,11} \mathrm{y}$ síntomas sistémicos entre los que se destacan las alteraciones en la hemostasia ${ }^{10}$. Los signos de envenenamiento sistémico se producen por ciertos componentes del veneno que afectan la integridad de los capilares sanguíneos y otros que causan alteraciones en la coagulación de la sangre, induciendo a hemorragia gingival, equimosis y coagulopatía por consumo del fibrinógeno plasmático ${ }^{4}$, entre otros.

Aunque los venenos botrópicos han sido ampliamente estudiados, es de interés complementar su caracterización extendiendo los estudios a su impacto en el sistema hemostático, especialmente por ser las serpientes responsables del mayor número de accidentes en Argentina ${ }^{6}$. 


\section{MATERIAL Y MÉTODOS}

Veneno empleado. Un pool de veneno obtenido de especimenes adultos de $B$. diporus fue obtenido de ofidios adultos sanos de la Provincia de Chaco (Argentina). Previa anestesia de los animales con dióxido de carbono, la extracción del veneno se realizó por compresión manual de las glándulas correspondientes, colocando los colmillos sobre un recipiente de vidrio esterilizado. Una vez obtenido, el veneno crudo fue desecado y conservado a $-20^{\circ} \mathrm{C}$ hasta el momento de ser utilizado. Para la realización de los ensayos el veneno se disolvió en buffer fosfato $\mathrm{pH}$ 7,2 (PBS). El material insoluble se separó por centrifugación, obteniéndose un sobrenadante límpido que se destinó a los ensayos.

Actividad coagulante del veneno. Se obtuvieron muestras de plasma de seres humanos, ovinos, caninos, bovinos y equinos, utilizando citrato de sodio al 3,8\% como anticoagulante. Se efectuaron diluciones seriadas del veneno, a partir de una solución madre $500 \mathrm{ug} /$ $\mathrm{ml}$ diluida en PBS pH 7,2. De cada dilución se tomaron $100 \mathrm{ul}$ y se agregaron $200 \mathrm{ul}$ de plasma previamente incubado a $37^{\circ} \mathrm{C}$. El tiempo de coagulación del plasma se determinó de visu, registrándose con un cronómetro. Cada determinación fue realizada por triplicado. El valor de la concentración coagulante mínima (CCM) se obtuvo graficando el logaritmo de la concentración de veneno versus el tiempo promedio de coagulación, acorde al método de Theakston ${ }^{25}$ modificado por Gené ${ }^{10}$. La CCM se define como la concentración de veneno final (ug/ml) que induce coagulación de plasma en $60 \mathrm{~s}$ bajo las condiciones descriptas.

Actividad fibrinolitica. Se trabajó con plasma citratado de origen ovino, bovino y equino. El plasma fue diluido con buffer Tris pH 7,5 en una dilución 1:2. Luego fue transferido en $22 \mathrm{ml}$ de la solución plasma-

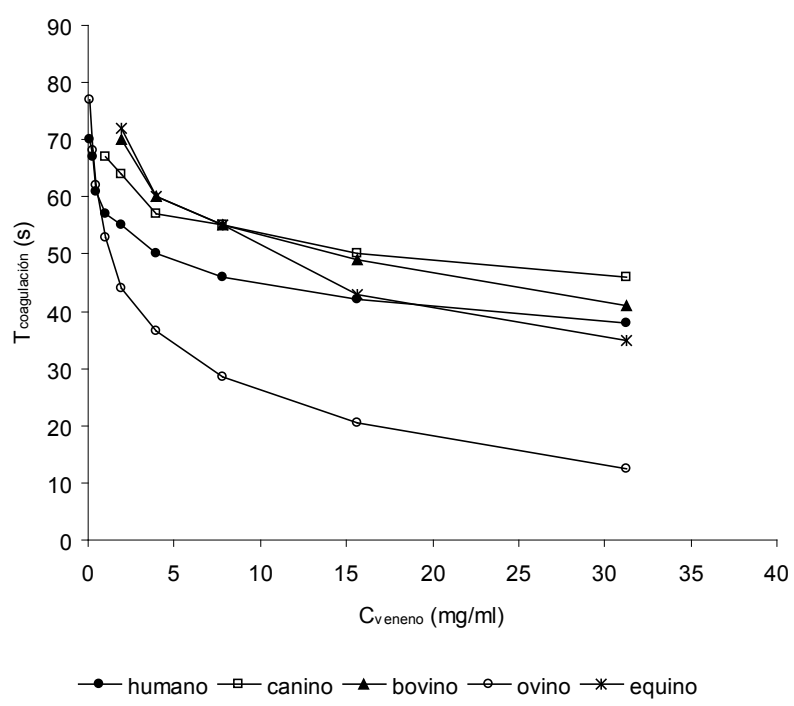

Figura 1. Acción coagulante de distintas concentraciones del veneno de $B$. diporus, sobre plasmas de origen humano, ovino, canino, bovino y equino. buffer a placas plásticas, adicionando $100 \mathrm{ul} \mathrm{de} \mathrm{solu-}$ ción de $\mathrm{CaCl}_{2} 0,25 \mathrm{M}$ y 6 ul de trombina humana. Se incubó a $37^{\circ} \mathrm{C}$ durante una hora. Se practicaron orificios de $2 \mathrm{~mm}$ de diámetro manteniéndose una distancia de $1,5 \mathrm{~cm}$ entre un pozo y otro. Se adicionaron $10 \mathrm{ul} \mathrm{de}$ las muestras de veneno para ser incubadas durante $18 \mathrm{~h}$ a $37^{\circ} \mathrm{C}$. Posteriormente se midió el área de fibrinolisis. La concentración fibrinolítica mínima (CFM) se define ${ }^{10}$ como la cantidad de veneno que induce un área de fibrinolisis de $12 \mathrm{~mm}^{2}$.

Actividad letal. Ratones blancos cepa CF1 de 18$20 \mathrm{~g}$ de peso corporal distribuidos en grupos de seis animales se inyectaron por vía intraperitoneal con veneno disuelto en solución salina $(\mathrm{pH} 7,2)$ en dosis que se incrementaron a través del factor 1,5. El volumen inyectado fue de $0,1 \mathrm{ml}$; los ratones controles recibieron $0,1 \mathrm{ml}$ de solución salina $(\mathrm{pH} \mathrm{7,2)} \mathrm{libre} \mathrm{de} \mathrm{veneno.}$ La supervivencia (dosis letal $50 \%, \mathrm{DL}_{50}$ ) fue registrada a las $48 \mathrm{~h}$.

Análisis estadístico. Los datos numéricos obtenidos fueron analizados con el programa Statistics 4.5 (Statsoft Inc.USA). Todos los experimentos fueron realizados por triplicado. La media de la $\mathrm{DL}_{50}$ del veneno y sus límites de confianza fueron calculados mediante el método de Spearman-Karber ${ }^{24}$. La concentración de proteína capaz de causar coagulación del plasma en 60 s, así como las actividades coagulante y fibrinolílitica, fueron estimados por regresión lineal, ajustada por el método del cuadrado mínimo.

\section{RESULTADOS Y DISCUSIÓN}

El veneno de $B$. diporus originaria del nordeste argentino causó desórdenes de la coagulación de la sangre de distintos mamíferos. En la Figura 1 se observa la curva dosis-respuesta de las distintas concentraciones del veneno incubado con los plasmas de mamíferos, en función del tiempo. A partir de estos datos se calculó la CCM para las distintas especies domésticas estudiadas y los valores obtenidos muestran que las especies ovina y humana fueron las más susceptibles, con CCM de $0,40 \mathrm{ug} / \mathrm{ml}\left(\mathrm{r}^{2}=0,98\right)$ y $0,50 \mathrm{ug} / \mathrm{ml}\left(\mathrm{r}^{2}=0,90\right)$ respectivamente. Los plasmas bovino y canino arrojaron valores sensiblemente más altos, pero similares entre sí $(3,90$ $\mathrm{ug} / \mathrm{ml}, \mathrm{r}^{2}=0,97$ y $3,60 \mathrm{ug} / \mathrm{ml}, \mathrm{r}^{2}=0,97$, respectivamente), en tanto que el plasma equino fue el mas resistente, al requerir mayor concentración de veneno para lograr coagular el plasma en $60 \mathrm{~s}(4,5 \mathrm{ug} / \mathrm{ml})\left(\mathrm{r}^{2}=0,94\right)$. Tales acciones se atribuyen a la presencia de enzimas tipo trombina en el veneno de $B$. diporus, capaces de convertir el fibrinógeno en fibrina.

El veneno estudiado indujo la coagulación del plasma de mamíferos, lo cual implica el potencial consumo de fibrinógeno en las víctimas del accidente ofídico provocado por B. diporus, situación que puede culminar en hemorragias por desfibrinación. En efecto, en la intoxicación por mordedura de dicha serpiente, uno de 
los síntomas consiste en hemorragias por consumo de fibrinógeno, las que pueden ser severas y poner en riesgo la vida del paciente, como ocurriera en un canino joven mordido por una serpiente del género Bothrops en la extremidad del miembro toráxico, que derivó en hemorragia del sistema nervioso central y muerte consecuente $^{2}$. Situaciones similares fueron reportados en la especie humana 14, 19, 23 .

Diversos autores valoraron la actividad coagulante de venenos de varios géneros y especies de serpientes americanas utilizando plasma de ovino (Tabla 1). De tal comparación surge que la más potente actividad coagulante correspondió al veneno de $B$. diporus, siguiéndole en orden de importancia el de Bothrops asper, serpiente que habita en regiones más cálidas (Centroamérica). Como indica la CCM, el resto de las especies consignadas posee venenos con menor actividad coagulante, al requerir dosis más altas para inducir la coagulación del plasma.

Es frecuente la existencia de diferencias en los componentes de la secreción salival de especies de serpientes del mismo género que comparten el mismo hábitat. Todas utilizan tal secreción para alimentarse y defenderse, sin embargo los efectos biológicos que causan son diferentes. Así, el veneno de Crotalus $d u$ rissus terrificus sudamericana posee escasa actividad coagulante, caracterizándose en cambio por su potente acción neurotóxica ${ }^{3,13,21}$ y la dosis necesaria para inducir la coagulación del plasma es muy alta (80 ug/ ml) de manera tal que en un accidente natural, dosis muy pequeñas de veneno pueden causar la muerte de la víctima sin que se evidencien clínicamente los efectos sobre la coagulación de la sangre ${ }^{16}$.

La culebra Philodryas patagoniensis habita la misma región geográfica que $B$. diporus y posee un veneno que no coagula el plasma de mamíferos, lo cual evidencia la ausencia de enzimas tipo trombina. Sin embargo es capaz de alterar la estructura del fibrinógeno, induciendo la degradación de sus cadenas alfa y beta, sin afectar la cadena gamma, efectos que pueden generar hemorragias al potenciarse dichos con la acción de otras proteínas del mismo veneno como las hemorraginas (metaloproteinasas), capaces de dañar los capilares sanguíneos ${ }^{20}$.

En la actividad fibrinolítica se presentaron diferencias numéricas entre los plasmas utilizados, respecto a la concentración de veneno necesaria para inducir la lisis de la fibrina in vitro (Tabla 2), siendo los plasmas de ovino y equino los más sensibles frente al veneno de Bothrops diporus.

Asimismo, los resultados aquí obtenidos demuestran que durante el envenenamiento por mordedura de $B$. diporus, la actividad del veneno podría estar involucrada no solamente en el consumo de fibrinógeno, sino también en la hidrólisis de microcoágulos formados poco tiempo después de la mordedura, demostrado con el método de fibrinolisis en placa (Tabla 3), en coincidencia con otras investigaciones ${ }^{5}$.
Tabla 1. Actividad coagulante de venenos de serpientes de Costa Rica (CR) y Argentina (A).

\begin{tabular}{|c|c|}
\hline especie & $\mathrm{CCM}(\mathrm{ug} / \mathrm{ml})$ \\
\hline Bothrops diporus * (A) & 0,40 \\
\hline Bothrops asper ** (CR) & 1,63 \\
\hline Bothrops schegeli $* *(\mathrm{CR})$ & 12,8 \\
\hline Bothrops alternatus $* * *(\mathrm{~A})$ & 14,5 \\
\hline Bothrops jararacussu $* * * *$ (A) & 18,5 \\
\hline Crotalus durissus durissus ** (CR) & 26,9 \\
\hline Bothrops nummifer** (CR) & 33,5 \\
\hline Bothrops godmani $* *(\mathrm{CR})$ & 64,5 \\
\hline Philodryas patagoniensis ${ }^{\#}$ (A) & $(-)$ \\
\hline Crotalus durissus terrificus ${ }^{\#}$ (A) & 80,0 \\
\hline
\end{tabular}

*este trabajo, **Gené 1989, ***Gay 2010, ****Maruñak 2006, "Peichoto 2007, "\# Maruñak (inédito).

Tabla 2. Actividad fibrinolítica del veneno de B. diporus.

\begin{tabular}{lc}
\hline plasma & CFM $(\mathrm{mg} / \mathrm{ml})$ \\
\hline ovino & $3,5(\mathrm{r}=0,87)$ \\
bovino & $9,0(\mathrm{r}=0,91)$ \\
equino & $3,0(\mathrm{r}=0,93)$ \\
\hline
\end{tabular}

Tabla 3. Actividad fibrinolítica de venenos de serpientes de Costa Rica (CR) y Argentina (A).

\begin{tabular}{|c|c|}
\hline serpiente & CFM (mg/ml) \\
\hline Bothrops godmani $*(\mathrm{CR})$ & 1,50 \\
\hline Crotalus durissus durissus * (CR) & 2,56 \\
\hline Bothrops nummifer* (CR) & 2,80 \\
\hline Bothrops asper * (CR) & 3,59 \\
\hline Bothrops diporus ** (A) & 3,50 \\
\hline Bothrops jararacussu \# (A) & 9,50 \\
\hline Bothrops alternatus *** (A) & 10,0 \\
\hline Bothrops moojeni ${ }^{\#}$ (A) & 10,0 \\
\hline Bothrops jararaca ${ }^{\# \#}(\mathrm{~A})$ & 10,2 \\
\hline Crotalus durissus terrificus ${ }^{\#}$ (A) & 30,0 \\
\hline Bothrops schegeli $*(\mathrm{CR})$ & 34,5 \\
\hline
\end{tabular}

*Gené 1989, **Este trabajo, ***Gay 2010, , Maruñak 2009, \#\#Maruñak (inédito).

Tabla 4. Comparación de actividades letales.

\begin{tabular}{lc}
\hline especie & $\mathrm{DL}_{50}$ \\
\hline B. diporus (NE, presente trabajo) & 38,18 \\
B. neuwiedii diporus (NO) & 26,60 \\
B. neuwiedii mattagrossensis (OB) & 49,00 \\
\hline
\end{tabular}

DL50: ug/20 g ratón, NE: nordeste argentino, NO: noroeste argentino, OB: oeste boliviano.

Los venenos de serpientes muestran actividades fibrinolíticas diferentes según su hábitat; sin embargo la actividad fibrinolítica del veneno estudiado en este trabajo, obtenido en ejemplares del continente sudamericano, resultó semejante a la actividad fibrinolítica exhibida por ejemplares centroamericanos ${ }^{10}$. Bothrops neuwiedii sudamericana es la serpiente cuyo veneno 
posee la mayor actividad fibrinolítica con relación a las restantes especies del mismo continente ${ }^{10}$.

Por otro lado, la capacidad de degradar tanto fibrinógeno como fibrina ha sido estudiada en venenos de varias especies de serpientes. Así, esta capacidad se detectó en veneno de $P$. patagoniensis, tanto in vitro como in vivo, en este último caso por provocar una disminución del fibrinógeno plasmático en ratas ${ }^{20}$. Ambas capacidades también fueron demostradas en Bothrops alternatus ${ }^{8,9}$ y Bothrops jararacussu ${ }^{17,18}$. Sin embargo la alteración de las cadenas del fibrinógeno no sería determinante para inducir hemorragias en el paciente accidentado, es probable que esta acción del veneno pueda ser causada por impedir la formación del tapón hemostático al interferir con los procesos de adhesión y agregación plaquetaria ${ }^{12,15}$.

Al comparar la actividad letal de $B$. diporus aquí obtenida en el nordeste argentino con la de $B$. neuwiedii diporus del noroeste argentino ${ }^{22}$ y con la de $B$. neuwiedii mattagrossensis del oeste boliviano ${ }^{22}$ surge que $B$. neuwiedii diporus posee el veneno más tóxico, al requerir menor cantidad de veneno para causar la muerte de los ratones empleados (Tabla 4). En consecuencia, es probable que la mordedura de ejemplares de B. neuwiedii diporus que habitan las provincias de Jujuy, Salta, Tucumán y Catamarca (noroeste argentino), sean capaces de provocar intoxicaciones mas severas.

Se concluye que el veneno de $B$. diporus del nordeste argentino altera la coagulación de la sangre al ejercer actividades coagulante y fibrinolítica. Además, es capaz de causar la muerte de la víctima, letalidad causada por la acción de los componentes coagulantes $\mathrm{y}$ anticoagulantes que culmina con el agotamiento del fibrinógeno plasmático.

\section{REFERENCIAS}

1. Acosta $\mathbf{O}$, Koscinczuk $\mathbf{P}$, Teibler $\mathbf{P}$, Sánchez Negrette $M$, Ruíz R, Maruñak S, Bogarín G. 1998. Actividades hemorrágica y edematizante y alteraciones histológicas en almohadilla plantar de ratón inducidas por venenos de serpientes de los géneros Bothrops y Crotalus de Argentina. Toxicon 36: 1165-1172.

2. Báez A, Teibler P, Merlo W, Burna A, Acosta M, Solana M, Infuleski R, Acosta O. 2005. Lesiones sistémicas en un canino por intoxicación ofídica. Rev Vet 16: 2, 95-98.

3. Brazil OV. 1980. Venenos ofídicos neurotóxicos. Rev Ass Med Brasil 26: 212-218.

4. Cardoso JL, Fan HW, França FO, Jorge MT, Leite RP, Nishioka SA, Ávila A, Sano IS, Tomy SC, Santoro ML. 1993. Randomized comparative trial of three antivenoms in the treatment of envenoming by lance-headed vipers (Bothrops jararaca) in Sao Paulo, Brazil. Q J Med 86: 315-325.

5. Escobar E, Rodriguez E, Yarlequé A. 1992. Isolation and partial characterization of a fibrinogenase from the venom of the peruvian bushmaster snake Lachesis muta. Adv Toxin Res 1: 421-430.
6. Esteso SC. 1985. Ofidismo en la República Argentina, Edit. Arpón, Cordoba, p. 82.

7. Fan HW, Cardoso JL. 1995. Clinical toxicology of snakes bites in South America. In: Handbook of toxicology of animal venom and poisons (Meier J, White J. Ed), CRC Press, Boca Raton (USA), p. 667-688.

8. Gay CC, Leiva LC, Maruñak S, Teibler P, Acosta O. 2005. Proteolytic, edematogenic and myotoxic activities of a hemorrhagic metalloproteinse isolated from Bothrops alternatus venom. Toxicon 46: 546-554.

9. Gay C. 2010. Aislamiento y caracterización de una metaloproteasa del veneno de Bothrops alternatus del nordeste argentino. Estudio de su fragmento de autólisis. Tesis de Doctorado, Facultad de Farmacia y Bioquímica, Universidad de Buenos Aires, $136 \mathrm{p}$.

10. Gené JA, Roy A, Rojas G, Gutiérrez JM, Cerdas L. 1989. Comparative study on coagulant, defribrinating, fibrinolytic and fibrinogenolytic activities of Costa Rican crotaline snake venoms and their neutralization by a polyvalent antivenom. Toxicon 27: 841-848.

11. Gutiérrez JM, Lomonte B. 1989. Local tissue damage induced by Bothrops snake venoms. A review. Mem Inst Butantan 51: 211-223.

12. Gutiérrez JM, Rucavado A. 2000. Snake venom metalloproteinases: their role in the pathogenesis of local tissue damage. Biochimie 82: 841-850.

13. Hundelson S, Hundelson P. 1995. Pathophysiology of snake envenomation and evaluation of treatment. Comp Small Anim 17: 889-897.

14. Kamiguti S, Sano IS. 1995. South American snake venoms affecting haemostasis. J Toxicol 14: 359-374.

15. Markland FS. 1998. Snake venoms and the hemostatic system. Toxicon 36: 1749-1800.

16. Maruñak S, Acosta O, Leiva L, Ruiz R, Aguirre MV, Teibler P. 2004. Mice plasma fibrinogen consumption by thrombin-like enzyme present in rattlesnake venom from the north-east region of Argentina. Revista Medicina (Buenos Aires) 64: 509-517.

17. Maruñak SL, Ruíz RM, Teibler GP, Gay C, Leiva L, Acosta O. 2006. Acción del veneno de Bothrops jararacussu de Argentina sobre la coagulación sanguínea. Invest Vet 8: 1-11.

18. Maruñak SL. 2009. Aislamiento y caracterización de una fosfolipasa $\mathrm{A}_{2} \mathrm{y}$ hemorragina del veneno de la serpiente Bothrops jararacussu. Tesis de Doctorado, Facultad de Ciencias Veterinarias, Universidad de Buenos Aires, 157 p.

19. Ouyang C, Teng CM, Huang TF. 1992. Characterization of snake venom components acting on blood coagulation and platelet function. Toxicon 30: 945-966.

20. Peichoto ME. 2007. Caracterización y aislamiento de proteínas del veneno de Philodryas patagoniensis que habita la región nordeste de Argentina. Tesis de Doctorado, Facultad de Farmacia y Bioquímica, Universidad de Buenos Aires, 173 p.

21. Rosenfeld G. 1971. Symptomatology, pathology and treatment of snake bites in South America. In: Venomous animals and their venoms (Bucherl W, Buckley E, Deulofeu V, Ed), Academic Press, New York, p. 345-384. 
22. Sanchez EF, Freitas TV, Ferreira DL, Velarde DT, Diniz MR, Cordeiro MN, Agostini G, Diniz CR. 1992. Biological activities of venoms from South American snakes. Toxicon 30: 95-103.

23. Seegers WH, Ouyang C. 1979. Snake venoms and blood coagulation. Handbook Exp Pharm 52: 684-750.
24. Spearman C, Karber G. 1981. Progress in the characterization of venoms and standarization of antivenoms. Publ. World Health Organization No 58, Ginebra, 44 p.

25. Theakston RD, Reid HA. 1983. The development of simple standard assay procedures for the characterization of snake venoms. Bull WHO 61: 949-956.

\section{Asociación Cooperadora de la Facultad de Ciencias Veterinarias}

Personería Jurídica No 647/92 y 912/00

Sargento Cabral 2139

3400 Corrientes

La Asociación Cooperadora de la Facultad de Ciencias Veterinarias fue constituida el 10 de diciembre del año 1991 como entidad de bien público, con el objeto de promover y coadyuvar las actividades científicas, educativas y culturales relacionadas con las Ciencias Veterinarias. En tal sentido, implementa acciones para colaborar con la enseñanza, extensión, actualización y difusión científica que realiza dicha Casa de Estudios.

\section{Beneficios que brinda a sus asociados:}

- Fotocopias con descuentos especiales del $20 \%$ en la Fotocopiadora COPIAS.COM que funciona dentro del predio de la Facultad de Ciencias Veterinarias.

- $10 \%$ de descuento para la adquisición de libros de la Editorial Inter-Médica.

- $10 \%$ de descuento en las compras de medicamentos e insumos para trabajos prácticos hospitalarios. 